\title{
Disease activity and need for dental care in a capitation plan based on risk assessment
}

\author{
I. Zickert, ' Å. Jonson, ${ }^{2}$ B. Klock, ${ }^{3}$ and B. Krasse, ${ }^{4}$
}

\author{
This article describes a capitation model of care which would \\ stimulate both dentists and patients to apply existing \\ preventive knowledge.
}

\begin{abstract}
$\boldsymbol{s}$ in most western countries, dental Ahealth has improved in Sweden, but the cost of dental care has increased. The reasons for this could include changes in the disease panorama, more teeth remaining in adults and the elderly, the demand for aesthetic restorations, good access to dental care and the amalgam scare. According to the Swedish Ministry of Health and Social Affairs, another important factor could be that the dental insurance system based on fee-for-service favoured expensive services rather than prevention. As both dental caries and periodontal disease can be effectively prevented ${ }^{1-4}$ an important challenge is to find a system, which would stimulate both dentists and patients to apply existing knowledge. After permission was granted by the Swedish Parliament a capitation plan was tested. The model was based on an assessment of the risk of future disease and the need for dental care. In principle, it is similar to the British private capitation system, Denplan. ${ }^{5}$ The study was performed in a public dental service clinic in the city of Göteborg. It started in the autumn of 1991 and this report covers observations made until the end of 1997.
\end{abstract}

\footnotetext{
${ }^{1}$ Head of the Public Dental Service, Göteborg, Medicinaregatan 12, 41390 Göteborg, Sweden; ${ }^{2}$ Senior Dental Surgeon, Public Dental Service, Göteborg, Sociala Huset 411 17, Göteborg, Sweden; ${ }^{3}$ Head of the Public Dental Service, County of Bohuslän, Box 275, 40124 Göteborg, Sweden; $4^{*}$ Emeritus Professor of Cariology, Institute of Odontology, Göteborg, Box 450, 40530 Göteborg, Sweden

${ }^{*}$ Correspondence to: B. Krasse

email:Bo.Krasse@odont.gu.se

REFEREED PAPER

Received 27.04.99; Accepted 12.09.00

(C) British Dental Journal 2000; 189: 480-486
}

\section{The patients}

All the patients who came to the clinic and had more than 16 remaining teeth were informed about the study and offered the chance to participate. About 50 per cent wanted to try the capitation model. Other patients entered the study as a result of information about the project in the newspapers and on the recommendation of other patients. This resulted in a study population in which most of the participants were less than 50 years old and 60 per cent were women (Table 1). Before being accepted for the capitation plan, all the patients had completed regular dental treatment. They had no acute oral diseases and were satisfied with their dental status. New patients were accepted continuously over a period of 3 years. In all, 3,114 patients participated in

\footnotetext{
In brief

- An important problem is to find a system which stimulates both the patients and the clinic to use preventive measures.

- A capitation model has been tested in which the 'carrot' for the patient is a reduced insurance fee at a reduced risk. For the clinic this meant that more patients could be taken care of, thereby increasing revenue.

- Practically all the patients stated that they preferred the capitation model of care fee-for-service. Also the dentists became with time very positive to the system and stated that the capitation model could serve as a model of care for dentistry in the future.

- The results indicate that gains can be made if preventive knowledge is effectively applied.
}

\begin{tabular}{|l|r|}
\hline \multicolumn{2}{|l|}{ Table I Review of the } \\
patient material \\
\hline Patients & 3,114 \\
\hline Males/females & $40 / 60 \%$ \\
\hline Age distribution (years) & \\
$20-29$ & $37 \%$ \\
$30-39$ & $35 \%$ \\
$40-49$ & $15 \%$ \\
$50-59$ & $7 \%$ \\
$60-69$ & $4 \%$ \\
$>69$ & $2 \%$ \\
Discharged or & $696(22 \%)$ \\
deregistered & \\
patients & \\
\hline Patients in risk group & \\
I & \\
II & $27-66 \%$ \\
III & $7-9 \%$ \\
& \\
\hline
\end{tabular}

the study. During the 6 years a total of 696 (22\%) patients left the study, most of them because they moved to other places. Other reasons were lack of interest, not showing up when summoned and economic reasons. Twenty-five patients were dismissed because of lack of compliance and 19 patients stated that they left the study because of dissatisfaction (Table 2).

\section{Risk assessment}

After weighting the criteria obtained from case history, clinical and radiographic examinations and supplementary laboratory examinations (Fig. 1), the patients were assigned to a low-, medium- or high-risk group. Over 60 per cent of the patients were assigned to the low-risk group and only 7 to 9 per cent to the high-risk one (Table 1). Salivary conditions and the level of caries-associated micro-organisms were determined using chair-side methods. ${ }^{6-8}$ The methods 


\section{Low-risk group}

Case history

No signs of illness

Good health

\section{Caries risk}

DMFT for each age group.*

Transfer to medium-risk group at the presence of $\mathrm{I}-2$ carious lesions, increased no. of cariogenic micro-organisms and salivary secretion rate of $<\mathrm{I} \mathrm{ml} / \mathrm{min}$.

\section{Perio risk}

Overall bone level coronary to the age projected bone level. ${ }^{\dagger}$ Bleeding at probing in $<20 \%$ of pockets, few pockets of $\geq 6 \mathrm{~mm}$. Transfer to medium-risk group if bleeding at probing in $<20 \%$ of pockets and increased no. of pockets of $\geq 6 \mathrm{~mm}$.

\section{Other risk factors}

Good oral hygiene. Few restorations with risk of fractures. No impacted third molars.

\section{Medium-risk group}

Case history

History of illness

Medication

\section{Caries risk}

DMFT for each age group.* Transfer to high-risk group at the presence of $\geq 3$ carious lesions, increased no. of cariogenic micro-organisms and salivary secretion rate of $\leq 0.5 \mathrm{ml} / \mathrm{min}$.

\section{Perio risk}

Mean bone level $\leq$ age projected bone level. $^{\dagger}$

Transfer to low-risk group if no bleeding in pockets $<20 \%$.

Good oral hygiene.

Transfer to high-risk group if bleeding at probing in $\geq 40 \%$ of pockets.

\section{Other risk factors}

Moderately good oral hygiene.

Extensive restorations with risk of fractures. One or more impacted third molars.

\section{High-risk group}

\author{
Case history \\ History of illness \\ Medication
}

\section{Caries risk}

DMFT for each age group.*

Transfer to medium-risk group at no new carious lesions, low no. of cariogenic microorganisms and salivary secretion rate of $\geq \mathrm{Iml} / \mathrm{min}$.

\section{Perio risk}

Mean bone level $\leq$ age projected bone level. ${ }^{\dagger}$ Several pockets of $\geq 6 \mathrm{~mm}$.

Transfer to medium-risk group if pockets of $\leq 4 \mathrm{~mm}$ and no bleeding, good oral hygiene.

*According to figures from the County of Bohuslän.

†According to the model described by Wennström et al. 1990 (Ref. I0)

that were used for recording dental caries and periodontal conditions and their prevention have been described previously. $1,4,9,10,11$

Initially, the patients paid an insurance premium of SEK 300, 650 or 1,000 depending on the risk assessment and the Swedish social insurance system paid a supporting subsidy of the same amount. After 2 years, both the insurance premium and the subsidy were changed in accordance with changes in the Swedish dental insurance system.

The capitation insurance plan covered examinations, treatment of the causes of disease, an individually designed preventive programme and general dental treatment. If crown and bridge work was required, the patient paid half the cost of the technical work and the total cost of the casting material. The dentist's work was covered by the capitation fee.

Table 2 Number and percentage of discharged patients and
reason for discharge

Other risk factors

Moderately good oral hygiene. Extensive restorations with risk of fractures and risk of endodontic treatment. One or more impacted third molars.

\begin{tabular}{|lcc|}
\hline Table 2 & $\begin{array}{c}\text { Number and percentage of discharged patients and } \\
\text { reason for discharge }\end{array}$ & \\
& & \\
& Number & Percentage \\
\hline Reason & 270 & 38.7 \\
Moving away & 110 & 15.8 \\
Did not pay & 97 & 13.9 \\
Did not show up & & \\
when summoned & 86 & 12.3 \\
Not interested & 67 & 9.6 \\
Too expensive & 25 & 3.6 \\
Did not comply & 19 & 2.7 \\
Dissatisfied & 13 & 1.9 \\
Deceased & 6 & 0.9 \\
Illness & 3 & 0.4 \\
Other insurance & & \\
Total & 696 & 99.8 \\
\hline
\end{tabular}




\section{PRACTICE preventive dentistry}

\begin{tabular}{|c|c|c|c|c|c|c|}
\hline \multirow[t]{2}{*}{ Table 3} & \multicolumn{6}{|c|}{$\begin{array}{l}\text { The average annual caries activity* in the patients in the different risk } \\
\text { groups after one (I) to six (VI) years }\end{array}$} \\
\hline & I & II & III & IV & V & $\mathrm{VI}^{\dagger}$ \\
\hline \multicolumn{7}{|c|}{ Risk group } \\
\hline Low & 0.2 & 0.2 & 0.2 & 0.2 & 0.2 & 0.1 \\
\hline Medium & 0.5 & 0.4 & 0.4 & 0.5 & 0.3 & 0.2 \\
\hline High & 0.7 & 0.8 & 0.8 & 0.7 & 0.7 & 0.1 \\
\hline \multicolumn{7}{|c|}{$\begin{array}{l}\text { *The sum of new decayed surfaces, including incipient carious lesions, surfaces with recurrent } \\
\text { decay and an increase in the size of previous carious lesions } \\
\text { †Only I I } 8 \text { patients examined }\end{array}$} \\
\hline
\end{tabular}

The staff, which consisted of four dentists, four dental hygienists (3.5 employed full time) and six dental nurses, was also responsible for the dental health service for children and youngsters up to 19 years of age in the area and for the treatment of patients who chose treatment according to the fee-for-service system. Thus, only part of the staff's working time was used for the patients in the capitation plan. At the beginning of the study the whole staff completed a course on modern methods for risk assessment, diagnosis, treatment and prevention of dental caries and periodontal diseases.

\section{Preventive measures}

When the patients had been accepted for the capitation plan, they received the necessary basic information, an individually designed preventive programme and were encouraged to try to stay free from dental caries and periodontal diseases by using self-administered home care. The preventive programme was both verbal and in writing (Appendix 1) and contained both recommendations of a basic character and some personal recommendations. They included prescriptions and special information. The patients were asked to get in touch with the clinic if they became seriously ill, had to start using med- ication or if something happened that affected their regular habits. The compliance of the patients was regularly checked. If necessary, the preventive programme was reinforced. It was stated in the insurance policy that the patients could be dismissed from the programme if they did not comply.

Once a year, the patients were re-examined and the same methods were used as when they entered the study. At signs of disease activity or increased risk (Fig. 1), the patient was transferred to a higher risk group and the preventive programme was strengthened. In the same way, a patient could be transferred to a lower risk group

\begin{tabular}{|c|c|c|c|c|c|c|}
\hline \multirow[t]{2}{*}{ Table 4} & \multicolumn{6}{|c|}{$\begin{array}{l}\text { The average number of tooth surfaces restored for reasons other than } \\
\text { caries per person and year in the different risk groups at re-examination } \\
\text { after one (I) to six (VI) years }\end{array}$} \\
\hline & 1 & II & III & IV & V & VI \\
\hline \multicolumn{7}{|c|}{ Risk group } \\
\hline Low & 0.4 & 0.5 & 0.6 & 0.6 & 0.6 & 0.7 \\
\hline Medium & 1.6 & 1.9 & 1.6 & 1.9 & 1.8 & 2.0 \\
\hline High & 2.4 & 2.5 & 2.6 & 3.2 & 2.7 & 3.0 \\
\hline
\end{tabular}




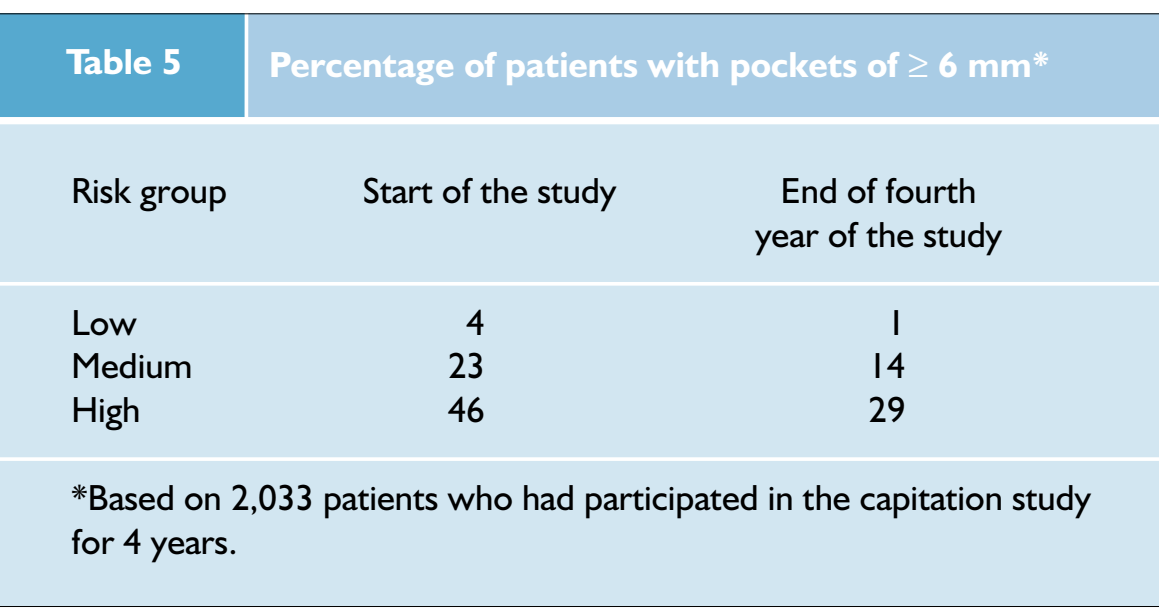

and, in accordance with a change of risk group, the insurance premium for the following year was changed.

Two-hundered-and-fifty-nine patients were assigned to another risk group at the re-examinations, 86 to a lower one and 173 to a higher one. Most of these changes took place at the re-examinations after 1 and 2 years. The greatest need for treatment was caused by fractures and other defects in old restorations. This has to be considered and given special weight in the risk assessment, a fact, which was not fully considered at the start of the study, and the main reason why patients were transferred to a higher risk group at the first annual reexaminations.

Totally 2,569 patients were followed for 3 years and 118 of 156 patients accepted from 1 October to 31 December 1991 were followed for 6 years. Only one of the 38 'lost patients' was dissatisfied.

\section{Disease activity}

The average caries activity - expressed as the sum of new decayed surfaces including incipient carious lesions, surfaces with recurrent caries and an increase in the size of previous carious lesions per person and year varied between 0.2 in the low-risk group and 0.8 in the high-risk group. Within the different risk groups, the average activity was about the same over the years (Table 3).

The average number of newly restored tooth surfaces per person and year varied between 0.4 and 3.2, with the highest figures being present in the high-risk group (Table 4). Most of these restorations had to be performed because of a need for retention, fractures and other defects in previous restorations. In a separate control examination of the 118 patients who had been in the capitation plan for 6 years, 33 per cent of the restorations had to be done because of caries.

The periodontal conditions improved in all the risk groups. At the start of the study, 46 per cent of the patients in the high-risk group had pockets of $\geq 6 \mathrm{~mm}$. After 4 years, the figure was 29 per cent. In the low-risk group, the corresponding figures were 4 and 1 (Table 5). One hundred and sixtyfour $(8 \%)$ out of 2,033 patients, who were followed for 4 years had gingival pockets $\geq$ $6 \mathrm{~mm}$. No teeth were extracted because of the progression of deep pockets. Only two patients developed five or more new pockets $\geq 6 \mathrm{~mm}$.

\section{Attitudes to the model}

The patients' attitude to the model and their behavioural changes were examined by a survey in questionnaire form. The questionnaire was administered to 907 patients who had participated in the capitation plan for more than 3 years. The staff's attitude to the capitation model was assessed by personal interviews. This survey was conducted by the

\begin{tabular}{|c|c|c|c|}
\hline \multirow[t]{2}{*}{ Table 6} & \multicolumn{3}{|c|}{$\begin{array}{l}\text { Disease activity iln randomly-selected capitation and } \\
\text { reference patients. Mean (SEM) }\end{array}$} \\
\hline & & $\begin{array}{l}\text { Capitation } \\
\text { patients }\end{array}$ & $\begin{array}{l}\text { Reference } \\
\text { patients }\end{array}$ \\
\hline \multicolumn{2}{|c|}{ Number of patients } & 100 & 100 \\
\hline \multicolumn{2}{|c|}{ DMFS at baseline } & 32.1 & 36.0 \\
\hline \multicolumn{2}{|c|}{ Caries activity $^{*}$} & $0.18(0.05)$ & $\mathrm{I} .74(0.34)$ \\
\hline \multicolumn{2}{|c|}{ Pockets of $\geq 6 \mathrm{~mm}^{\dagger}$} & $0.04(0.02)$ & $0.31(0.09)$ \\
\hline \multicolumn{2}{|c|}{ Bleeding pockets $\ddagger$} & $0.02(0.01)$ & $0.16(0.06)$ \\
\hline \multicolumn{4}{|c|}{$\begin{array}{l}\text { *Average number of new decayed surfaces, including incipient carious } \\
\text { lesions, surfaces with recurrent caries and an increase in the size of } \\
\text { previous carious lesions } \\
\text { †Average number of gingival pockets } \geq 6 \mathrm{~mm} \\
\text { ҒAverage number of gingival pockets with bleeding }\end{array}$} \\
\hline
\end{tabular}




\section{PRACTICE preventive dentistry}

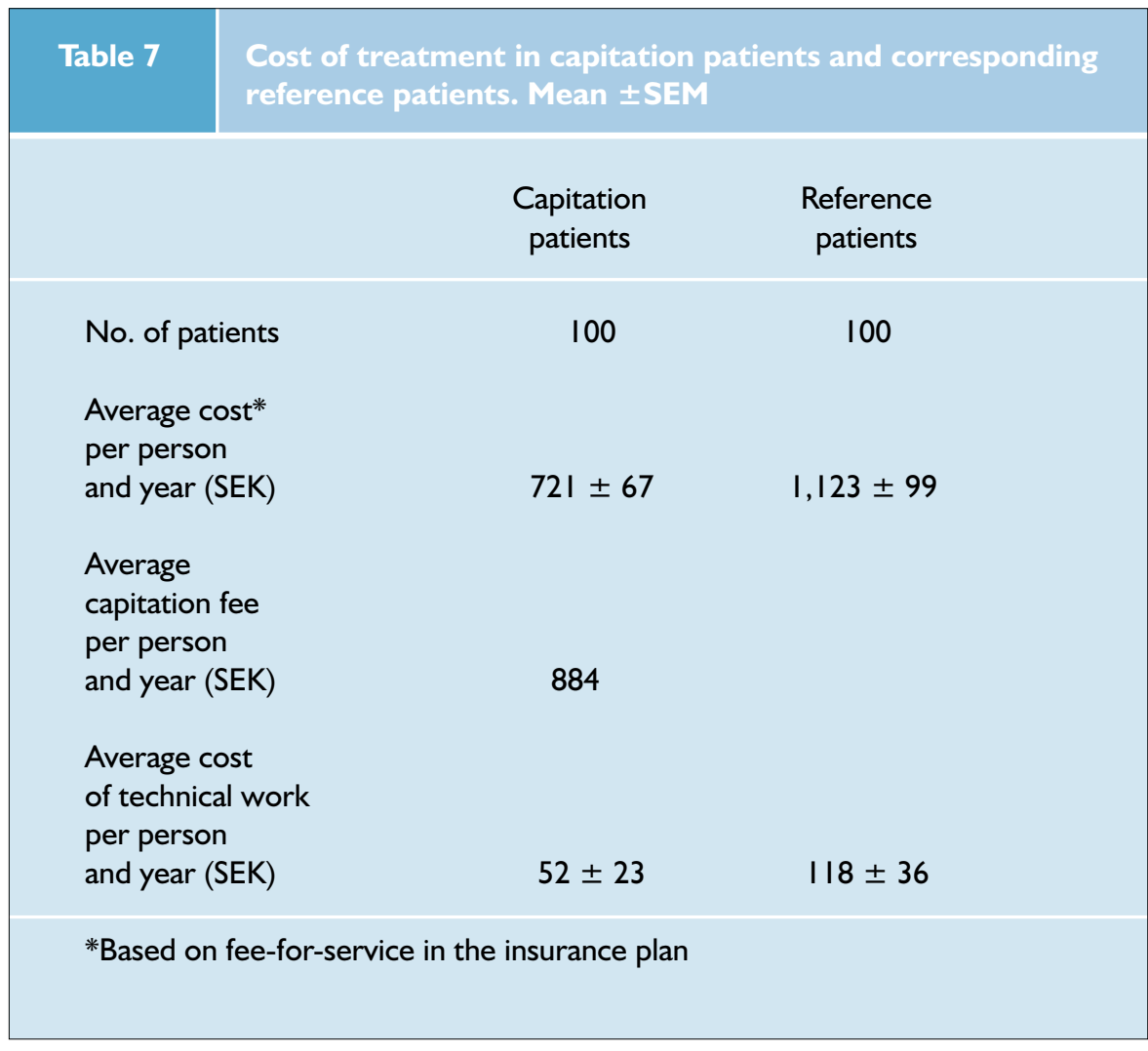

occupational health service in Göteborg.

Some 83 per cent of the patients answered the questionnaire about their attitudes to the model, and 98 per cent of them stated that they preferred the capitation model of care to fee-for-service. They claimed that they had obtained increased awareness of oral hygiene, the importance of dietary habits and self-administered home care. Fifty-eight per cent stated that they had changed their oral hygiene habits, and 26 per cent stated that they more regularly used fluoride rinsing. Twenty-four per cent stated that they had reduced their in-between meal eating of sugar and 44 per cent that they had increased their intake of sugar substitutes. Seventyfour per cent stated that they felt an increased sense of participation in their own dental care. Eighty-five per cent of the patients stated that the insurance fee was just right or low in relation to the dental care which they received.

Among the staff, the dental hygienists were the most positive. The dental nurses were also positive, but they wanted more clinical responsibility. The dentists who mainly became involved in restorative care at the start were critical. They then felt that they lost some important personal contact with the patients. As time passed they became, however, more positive and stated that this capitation model of care could serve as a model for dentistry in the future.

\section{Capitation versus fee-for-service}

For dentists working in or thinking of joining a capitation scheme a comparison between capitation patients and patients from fee-for-service public dental clinic could be of interest. Such a comparison was therefore made. As the study was not designed as a randomised clinical trial and the data not collected under rigidly controlled conditions statistical analysis of the figures provided would be inappropriate. Thus, the results of the comparison described below are entirely descriptive.

The fee-for-service clinic served a population with a similar socio-economic back- ground as the capitation clinic. Laboratory examinations were seldom used. The patients, who were compared, had been patients at their respective clinic for at least three years. At the fee-for-service clinic the patients were selected in the following way. Starting on a certain date, the first 100 patients were selected and examined until a sample was obtained with the same proportion of men and women in different age groups as the population in the capitation study. Among the capitation patients, men and women whose date of birth was closest to that of the person in the fee-for-service group, were then selected. The methods used for recording of dental caries and periodontal disease were those recommended by the Board of Health and used in the public dental service. Before the examinations started at the fee-for-service clinic, the dentists at this clinic were carefully informed about the criteria. The clinical data were then compared and the results are shown in Table 6. The economic data from the patient records at the capitation and the fee-for-service-clinic were also compared. The real cost for the patients in the capitation group was calculated on the basis of fee-for-service in the Swedish dental insurance system. The cost of information and other preventive measures was based on the time consumed by these services according to the insurance system. The average yearly cost per patient was based on the cost of treatment during a period of 3 years. The average yearly capitation fee obtained from the patients was also calculated.

The average cost per person and year was lower in the capitation patients than in the patients from the reference clinic. The income, ie the average capitation fee per patient, was, however, higher than the average cost of treatment. The average cost of technical work was lower for the capitation patients than for the fee-for-service patients (Table 7).

An auditor outside the public dental service examined the total cost of the capitation study. According to his report, the capitation system produced a slightly better economic result than the fee-for-service system, when the running-in period had been completed. 


\section{Discussion}

The most interesting result of this study is that 98 per cent of the patients stated that they preferred the capitation model of care to fee-for-service. Another important observation was that both dental caries and periodontal disease could be controlled in the majority of the patients. Not even in the high-risk group did the average total caries activity reach one surface per person and year (Table 3 ).

The positive clinical results are most probably explained by the changes in attitudes and behaviour among the patients. They claimed that they had obtained an increased awareness of oral hygiene and realised the importance of dietary habits and use of fluorides. This in turn was a result of the careful information, the individually designed preventive programme and monitoring the effect of the preventive measures - all services included in the capitation fee. An important reason why the patients preferred the capitation model of care to feefor-service was probably the knowledge about the fee for the following year.

When assigning a new patient to a certain risk group, laboratory tests were performed on the new patients during the first 2 years. These tests were also applied when monitoring the effect of the individually tailored preventive measures. This appears to have been important, both for stimulating the compliance of the patient and for improving the skill of the staff in the art of health education. Another important factor probably was that the individually designed preventive programme was given both verbally and in writing. The value of this has recently been stressed by Raynor. ${ }^{12}$ Another reason for the positive clinical results could be that the patients volunteered to participate and came to the capitation clinic as a result of information about the project. They might therefore have been primarily interested in the prevention of their dental diseases.

Another explanation for the positive results are the attitude changes among the staff members. When they realised that the capitation system, which they had applied in the school dental service, also worked in adults, they became very positive to the cap-

\section{Appendix I Your dental health programme}

You have been assigned to the HIGH risk group.

We regard your risk of dental disease and the future need for dental care as high. With self-administered home care and our help, you can reduce the risk of developing dental disease. Our recommendations are partly of a basic character and partly individually designed.

Firstly, some recommendations of a basic character.

- Avoid eating things containing ordinary sugar between meals. Be aware of so-called risk products such as chewing gum, lozenges and soft drinks. Remember that products which contain sugar substitutes such as xylitol, sorbitol and aspartame are available.

- Make use of the caries-preventive effect of fluoride. Brush your teeth twice a day with fluoride toothpaste.

- In addition, use interdental cleaners or dental floss to clean between your teeth according to instructions.

\section{Our special recommendations for you}

Reduce the causes of dental disease by:

- Changing your dietary habits in accordance with our counselling.

- Improving your oral hygiene habits in accordance with our recommendations.

- Trying to reduce a high number of caries-associated bacteria.

Prescription and information are enclosed.

Increase your resistance to disease by:

- Increasing the use of fluoride

- Trying to stimulate the salivary secretion rate.

Prescription and information are enclosed.

Get in touch with us if you become seriously ill or have to take medicines regularly.

You will be called for a check-up in the month of and before your insurance period runs out. 
itation model of care. This is illustrated by the fact that they have continued to apply it.

The intended 'carrot' for the patient was a reduced capitation fee at a lower risk and, as far as the clinic was concerned, this meant that more patients could be taken care of, thereby increasing revenue. It soon became obvious, however, that there was a need for more than three risk groups in order to stimulate the compliance of the patients. On the basis of the experience acquired in this study, a new system is now being applied at the test clinic as well as at other public dental service clinics in Göteborg. Each of the original three risk groups has been split in two and the groups now vary from very low to very high risk with six corresponding levels for the yearly insurance fee. In this context, it should be noted that five categories are used in the Denplan system. ${ }^{5}$

The comparison between selected patients from the capitation study and the fee-for-service clinic are interesting (Tables 6 and 7). The data might stimulate a randomised clinical trial in which the methods described in the present model are applied. The data support the conclusion drawn by Holloway and Clarkson that prevention can be cost:beneficial when practised selectively. ${ }^{13}$

It is not likely that the low disease activity in the capitation patients was a result of 'supervised neglect'. Capitation has been used for decades in the Swedish school dental service and official epidemiological data do not indicate any supervised neglect. When the patient in the present study came for a check-up and indications of disease or increased risk was observed, the preventive programme was strengthened. Furthermore, in the written individual preventive programme, the patients were recommended to get in touch with the clinic if something happened that affected their regular habits. As stated earlier, practically all the patients liked the capitation model of care and continued to have a low need of treatment. In a capitation study involving adolescents in Great Britain, little evidence of 'supervised neglect' was observed. ${ }^{14}$
The results of this study show that methods developed at faculty clinics can also function in the public dental health service. Practically all the patients preferred the capitation model of care rather than fee-forservice. A medical model like the one in the present study has been suggested by American authors ${ }^{15}$ and Mike Grace, the editor of this journal, has stated: 'after all it makes sense to heal and prevent rather than simply build up an edifice while the fire that destroyed it is still raging. ${ }^{16}$ In order to achieve a long-term improvement in oral health, however, not only support from the community and an insurance system but also from friends and families appears to be necessary. ${ }^{17,18}$

\section{Conclusions}

- Methods developed at faculty clinics for risk assessment can function also in a public dental service clinic in Sweden.

- Both dental caries and periodontal disease could be controlled in the majority of patients.

- The greatest need for treatment was caused by fractures and other defects in old restorations.

- Ninety-eight per cent of the patients stated that they preferred the capitation model of care to fee-for-service.

- The positive results are most probably explained by the attitude changes among the patients.

- The capitation model of care stimulated both dentists and patients to apply existing prevention knowledge.

A committee appointed by Dr Runo Ögren and Dr Holger Nilson, former directors of the public dental service in the City of Göteborg and the County of Bohuslän respectively, planned this project. Mrs Ulla Y Gustafsson served as its secretary. The initiative of these persons is greatly appreciated and, thanks to their dedicated work, the project became a reality. Representatives from the Ministry of Health and Social Affairs, the Board of Health and Social Welfare, the National and Local Insurance System, the City of Göteborg and the County of Bohuslän followed the study. The study could never have been completed without the strong and loyal support of the staff at the clinics. We would like to acknowledge this and extend our special thanks to Dr Gun Britt Eliasson in Göteborg for her meticulous work with the data.
1 Axelsson P, Lindhe J, Nyström B. On the prevention of caries and periodontal disease in adults. Results of a 15 year longitudinal study in adults. J Clin Periodontal 1991; 18:182-189.

2 Echeverria J J. How to integrate prevention into a successful pratice. Int Dent J 1994; 44: 312316.

3 Petersson G H, Bratthall D. The caries decline: a review of reviews. Eur J Oral Sci 1996; 104: 436-443.

4 Rask P I, Emilson C G, Krasse B, Sundberg H. Effect of preventive measures in 50-60 yearolds with high risk of dental caries. Scand J Dent Res 1988; 96: 500-504.

5 Dental care assessment and contract. Denplan Ltd 1996; Denplan Court, Victoria Road, Winchester SO23 7RG, Great Britain.

6 Ericsson D, Bratthall D. Simplified method to estimate buffer capacity. Scand J Dent Res 1989; 97: 405-407.

7 Larmas M A. A new dipslide method for the counting of salivary lactobacilli. Proc Finn Dent Soc 1975; 71: 31-35.

8 Jensen B, Bratthall D. A new method for the estimation of mutans streptococci in human saliva. J Dent Res 1989; 68: 468-471.

9 Fure S, Zickert I. Root surface caries and associated factors. Scand J Dent Res 1990; 98: 391-400.

10 Wennström J L, Papapanou P N, , Gröndahl K. A model for decision making regarding periodontal treatment needs.J Clin Periodontol 1990; 17: 217-222.

11 Krasse B. Caries Risk. A Practical Guide for Assessment and Control. Quintessence Publ. Co Inc. Chicago, London, Berlin. 1985.

12 Raynor D K. The influence of written information on patient knowledge and adherence to treatment. In Myers L B and Midence K. Adherence to treatment in medical conditions. pp83-112. Harwood Academic Publishers UK, 1998.

13 Holloway P J, Clarkson J E. Cost:benefit of prevention in practice. Int Dent J 1994; 44 : 317-322.

14 Holloway P J, Lennon M A, Mellor A C, Coventry P, Worthington H V. The capitation study. 1. Does capitation encourage supervised neglect? Br Dent J 1990; 168 : 119-121.

15 Anderson M H, Bales D J, Omnell K-Å. Modern management of dental caries: The cutting edge is not the dental bur. J Am Dent Ass 1993; 124: 37-44.

16 Grace M. Leader: Dental megatrends. Br Dent J 1995; 178: 319

17 Watt R G, Fuller S S. Oral health promotion opportunity knocks. Br Dent J 1999; 186: 3-6.

18 Sheiham A. Oral health policy and prevention. In Murray J J. The prevention of oral disease. pp234-249. Oxford University Press, 1999. 